\title{
Anti-Parkinson Drug Biperiden Inhibits Enzyme Acetylcholinesterase
}

\author{
Adam Kostelnik, ${ }^{1,2}$ Alexander Cegan, ${ }^{1}$ and Miroslav Pohanka ${ }^{2}$ \\ ${ }^{1}$ Faculty of Chemical Technology, University of Pardubice, Studentska 95, 53210 Pardubice, Czech Republic \\ ${ }^{2}$ Faculty of Military Health Sciences, University of Defence, Trebesska 1575, 50001 Hradec Kralove, Czech Republic \\ Correspondence should be addressed to Miroslav Pohanka; miroslav.pohanka@gmail.com
}

Received 28 March 2017; Revised 24 May 2017; Accepted 19 June 2017; Published 13 July 2017

Academic Editor: Sherry L. Mowbray

Copyright (c) 2017 Adam Kostelnik et al. This is an open access article distributed under the Creative Commons Attribution License, which permits unrestricted use, distribution, and reproduction in any medium, provided the original work is properly cited.

\begin{abstract}
Biperiden is a drug used in Parkinson disease treatment and it serves also as an antiseizures compound in organophosphates poisoning. It acts as antagonist of muscarinic receptor activated by acetylcholine while the enzyme acetylcholinesterase (AChE) cleaves acetylcholine in synaptic junction into choline and acetic acid. This enzyme is inhibited by various compounds; however there has not been proposed evidence about interaction with biperiden molecule. We investigated this interaction using standard Ellman's assay and experimental findings were critically completed with an in silico prediction by SwissDock docking software. Uncompetitive mechanism of action was revealed from Dixon plot and inhibition constant $\left(K_{i}\right)$ was calculated to be $1.11 \mathrm{mmol} / \mathrm{l}$. The lowest predicted binding energy was $-7.84 \mathrm{kcal} / \mathrm{mol}$ corresponding to $\mathrm{H}$-bond between biperiden molecule and Tyr $341 \mathrm{residuum}$ in protein structure of AChE. This interaction seems to be further stabilized by $\pi-\pi$ interaction with Tyr 72 , Trp 286 , and Tyr 341 . In conclusion, biperiden appears as a very weak inhibitor but it can serve as a lead structure in a pharmacological research.
\end{abstract}

\section{Introduction}

Termination of neurotransmission in cholinergic nerves or neuromuscular junctions is done by an enzyme AChE. Mechanism of action is in cleaving of acetylcholine, neurotransmitter interacting with acetylcholine muscarinic receptor $(\mathrm{mAChR})$ and nicotinic receptor (nAChR) $[1,2]$. AChE is a target for many toxic compounds like organophosphorus and carbamate pesticides (e.g., parathion, malathion, and carbofuran), warfare agents (e.g., sarin, soman, and VX), or some toxins like aflatoxin B1 [3-7]. Big and important group of AChE inhibitors is created by anti-Alzheimer drugs as donepezil, galantamine, rivastigmine, or huperzine A [8-10].

Biperiden also known under tradename Akineton ${ }^{\circledR}$, a compound with proper chemical name alphabicyclo[2.2.1] hept-5-en-2-yl-alpha-phenyl-1-piperidinepropanol (Figure 1), is an anticholinergic drug used in treatment of Parkinson disease and neuroleptic-induced extrapyramidal motor side effects [11]. It acts as a muscarinic receptor antagonist with high affinity for the M1 muscarinic receptor
[12]. Furthermore, it can be used as antiseizures compound in poisoning by organophosphates $[13,14]$.

Despite the fact that biperiden is used in therapy of parkinsonism, there is no evidence about possible interaction with AChE itself. Some structural motives in the biperiden resemble another AChE inhibitor, compound known as huperzine $\mathrm{A}$. The fact leads us to the idea that biperiden can act as inhibitor and we hypothesize a possible interaction with AChE.

\section{Material and Methods}

2.1. Chemicals. Acetylcholinesterase as lyophilized powder (electric eel, activity $\geq 1000$ units/mg of protein), acetylthiocholine chloride, $5,5^{\prime}$-dithiobis(2-nitrobenzoic) acid (DTNB), and phosphate buffer saline (PBS) 7.4 were purchased from Sigma-Aldrich (St. Louis, MO, USA). Biperiden lactate $(5 \mathrm{mg} / \mathrm{ml})$ in one-milliliter ampules was obtained from Knoll AG (Ludwigshafen, Germany). Deionized water was prepared by Aqua Osmotic device (Tisnov, Czech Republic). 


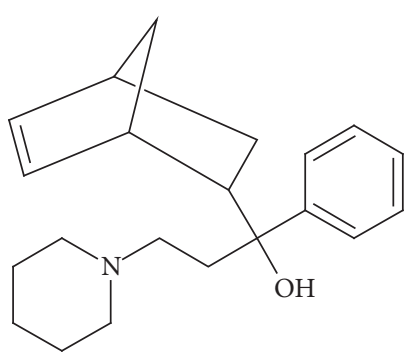

FIGURE 1: Chemical structure of biperiden molecule.

2.2. Enzymatic Assay with Biperiden. Ellman's method was chosen for the enzyme activity assay and it was performed as follows: $400 \mu \mathrm{l}$ of DTNB, $25 \mu \mathrm{l}$ of AChE, $375 \mu \mathrm{l}$ of PBS 7.4, $100 \mu \mathrm{l}$ of PBS 7.4 or biperiden, and $100 \mu \mathrm{l}$ of acetylcholine chloride were pipetted into standard spectrophotometric cuvette. Absorbance was measured immediately after addition of substrate and then after $2 \mathrm{~min}$ of reaction. Enzyme activity was then calculated using extinction coefficient for 5-thio-2-nitrobenzoic acid $\varepsilon=14,1501 \times \mathrm{mol}^{-1} \times \mathrm{cm}^{-1}$ [15]. Concentration of biperiden was calculated to whole volume of reaction medium in cuvette.

2.3. Data Processing. Dixon plot was created in Origin software (OriginLab, Northampton, MA, USA). $K_{i}$ for uncompetitive inhibition was calculated from Dixon plot as follows: Slope $=1 / V_{\max } \times K_{i} . V_{\max }$ for AChE was obtained experimentally (as described in previous section) and calculated in Origin software (OriginLab, Northampton, MA, USA) using nonlinear Hill fitting with coefficient of cooperativity $n=1$.

2.4. Docking of Biperiden to AChE. SwissDock server (Swiss Institute of Bioinformatics, University of Lausanne, Switzerland) was used for in silico prediction of the lowest free binding energy. The calculation was running online (accessible from http://www.swissdock.ch/) in the Internet browser. Crystal structure of AChE (1C2B) [16] was taken in PDB format and biperiden ligand in ZINC format as required for calculation [17]. UCSF Chimera 1.11.2 software was used for visualization of the results and creating $3 \mathrm{D}$ images.

\section{Results and Discussion}

Biperiden proved to be inhibitor of $\mathrm{AChE}$ as seen from the results. From Dixon plot, uncompetitive mechanism of AChE inhibition was revealed (Figure 3 ). This type of inhibition is very rare and it is more probable for multifold substrate reactions. More typical mechanism for AChE is noncompetitive or competitive inhibition [18]. $K_{i}$ for biperiden and AChE was calculated to be $1.11 \pm 0.20 \mathrm{mmol} / \mathrm{l}$, which equals $\mathrm{IC}_{50}$ in this type of inhibition [19]. Figure 2 is displaying saturation curve from which $V_{\max }$ for $K_{i}$ calculation was obtained as described above. Data obtained from experiment are summarized in Table 1.

Interaction of biperiden with AChE was studied using SwissDock server. The lowest binding energy $\Delta G$ was equal to $-7.84 \mathrm{kcal} / \mathrm{mol}$ and corresponds to interaction between
TABLE 1: Data from inhibition assay.

\begin{tabular}{lccc}
\hline $\begin{array}{l}\text { Substrate } \\
(\mathrm{mM})\end{array}$ & Slope $\left(\mathrm{s} \times \mathrm{l} / \mathrm{mol}^{2}\right)$ & $\begin{array}{c}\text { Interception } \\
(\mathrm{s} / \mathrm{mol})\end{array}$ & $\begin{array}{c}\text { Correlation } \\
\text { coefficient }\end{array}$ \\
\hline 1.0 & $1.30 \times 10^{9}$ & $1.60 \times 10^{6}$ & 0.9647 \\
0.50 & $1.55 \times 10^{9}$ & $1.75 \times 10^{6}$ & 0.9978 \\
0.25 & $1.87 \times 10^{9}$ & $2.05 \times 10^{6}$ & 0.9965 \\
\hline
\end{tabular}

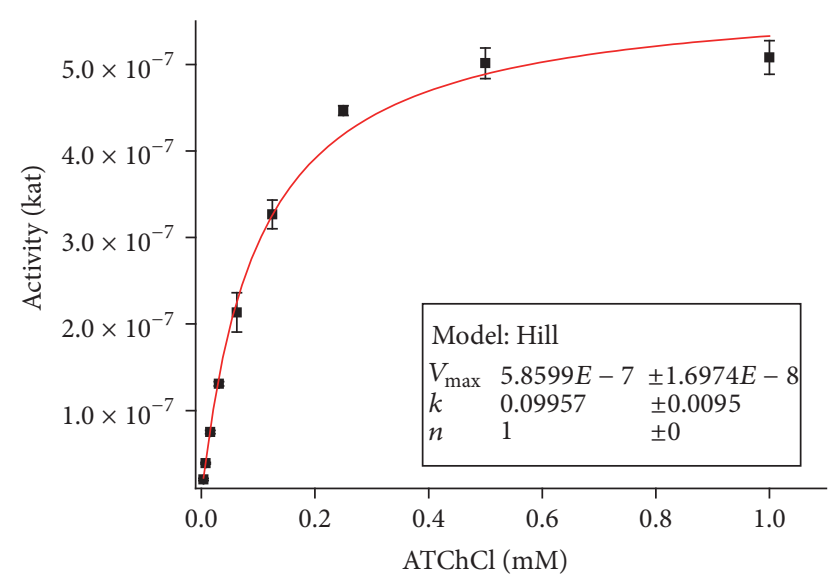

FIGURE 2: Saturation curve for AChE and acetylthiocholine as a substrate. Error bars indicate standard deviation for $n=3$.

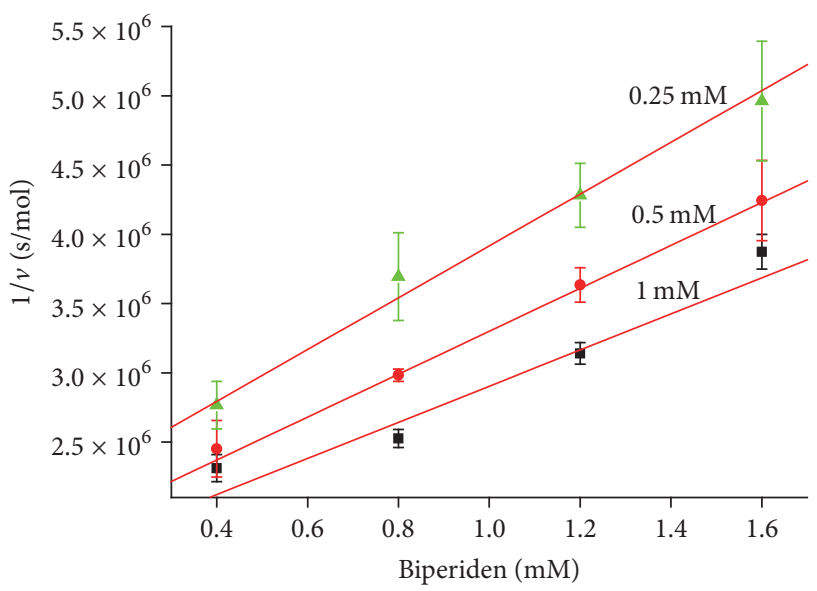

FIgUre 3: Dixon plot for AChE with different concentrations of substrate (indicated above each line). Error bars indicate standard deviation for $n=3$.

biperiden and peripheral anionic subsite. In the lowest energy, there is predicted $\mathrm{H}$-bond between hydroxyl group in biperiden molecule and $\mathrm{O}$ atom in Tyr 341 (2.24 $\AA$ ). This seems to be stabilized by $\pi-\pi$ interaction of benzene ring in biperiden with aromatic amino acids of peripheral anionic subsite Tyr 72 (3.43 $\AA$ ), Trp 286 (3.18 $\AA$ ), and Tyr $341(3.05 \AA)$ (Figure 4). As seen from the quoted papers $[20,21]$, T-shape geometry (or face to age) interaction is the most common between two aromatic systems and it was found to be most abundant interaction in present work. On the other hand, face to face interaction is very rare 
TABLE 2: Found results about biperiden interaction with AChE.

\begin{tabular}{lc}
\hline Parameter & Findings \\
\hline Mechanism of inhibition & Uncompetitive \\
Inhibition constant (equal to $\mathrm{IC}_{50}$ in this kind of inhibition) & $1.11 \pm 0.20 \mathrm{mmol} / 1$ \\
Predicted binding energy $\Delta G$ & $-7.84 \mathrm{kcal} / \mathrm{mol}$ \\
& H-bond: Tyr 341 \\
Predicted interactions & $\pi-\pi$ interaction: Tyr 72 , Trp 286, Tyr \\
& 341 \\
\hline
\end{tabular}

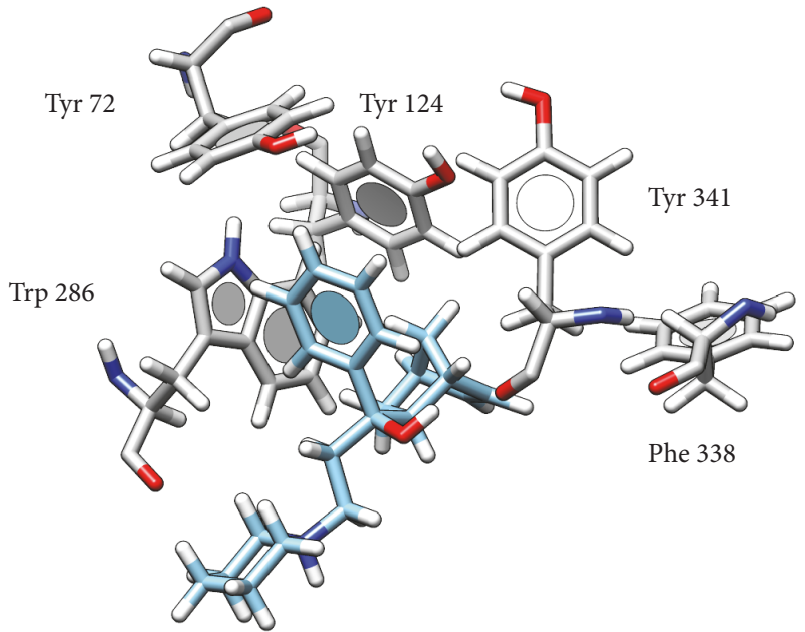

Figure 4: Possible interaction of biperiden with AChE. Atom color: white $=\mathrm{H}$, grey (in AChE) or light blue (in biperiden $)=\mathrm{C}$, blue $=$ $\mathrm{N}$, and red $=\mathrm{O}$.

due to electrostatic repulsion and it was not observed in this study. As bicycloheptenyl contains double bond, it does not seem to provide any further stabilizing effect. There are conformational changes in protein structure after binding of substrate, leading to decrease of the distance between Phe 338 and Tyr 124 as proved works with 4-oxo-N,N,Ntrimethylpentanaminium (acetylcholine analogue) [22]; thus these residues could become active in interaction with this double bond in bicycloheptenyl structure. Conformational changes are fundamental and would explain uncompetitive mechanism of inhibition. Nevertheless, this interaction is alleged and more investigation should be done prior to this conclusion. Results from experiment are summarized in Table 2.

There is another possible interaction followed with release of free binding energy $\Delta G=-7.58 \mathrm{kcal} / \mathrm{mol}$, where $\mathrm{H}$-bond $(2.24 \AA)$ is also predicted between biperiden hydroxyl and O atom in Tyr 341. Additionally, further stabilization seems to be provided by $\pi-\pi$ interaction of benzene ring in biperiden with $\operatorname{Trp} 286$ (3.18 $\AA$ ), Tyr 341 (3.96 $\AA$ ), and Phe 338 (4.01 $\AA$ ) in peripheral anionic subsite and cation- $\pi$ interaction with Tyr 124 (5.84 $\AA$ ) of AChE (Figure 5).

Biperiden was shown to be weak inhibitor of AChE. For example, most common used cholinesterase's inhibitors like tacrine or donepezil are, respectively, almost 18,500 times and 300,000 times stronger inhibitors of AChE than

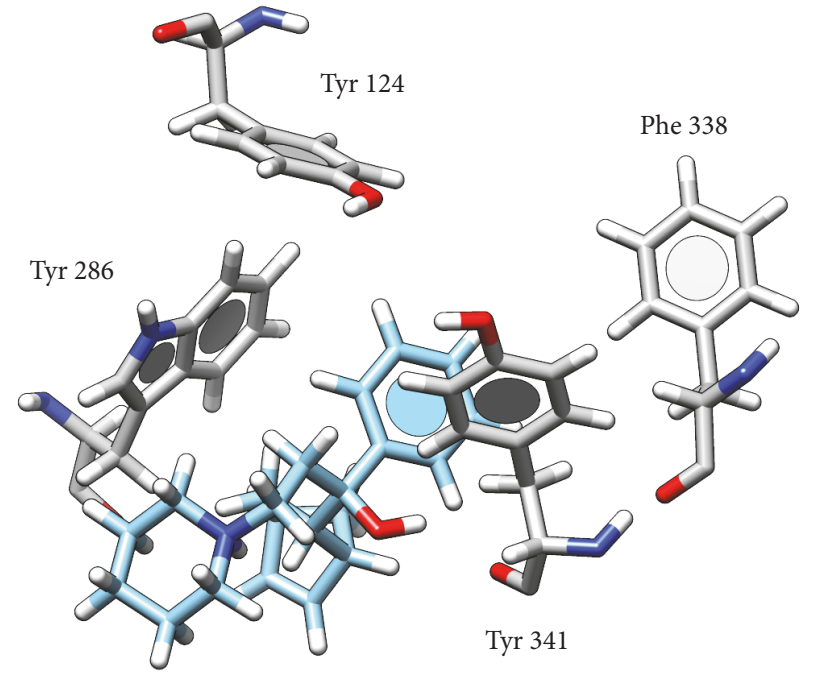

FIgURE 5: Possible interactions of biperiden with $\beta$-anionic site of AChE. Atom color: white $=\mathrm{H}$, grey (in AChE) or light blue (in biperiden $)=\mathrm{C}$, blue $=\mathrm{N}$, and red $=\mathrm{O}$.

biperiden [23]. Limited data about biperiden in humans are available. Presumed plasma concentration of biperiden of $5 \mathrm{ng} / \mathrm{ml}(16 \mathrm{nmol} / \mathrm{l})$ is reached after 1.5 hours when two $2 \mathrm{mg}$ tablets are taken [24]. Typical daily dose is ranging between 2 and $8 \mathrm{mg}[25,26]$. However, for causing significant decrease of AChE activity, $342 \mu \mathrm{g} / \mathrm{ml}(1.1 \mathrm{mmol} / \mathrm{l})$ is needed as we found out in present work; this means approx. $14 \mu \mathrm{mol} / 1$ for average weight person $(80 \mathrm{~kg})$. For humans $\mathrm{LD}_{50}$ is not available; for animal models, for example, for rats it is $750 \mathrm{mg} / \mathrm{kg}$ (orally); it is approx. $3.0 \mu \mathrm{mol} / \mathrm{l}$ in molar scale. As seen above, for inhibition effect of AChE almost 69,000 times higher dose compared to therapeutic one is required; moreover toxic effect is observed at the same level as needed for causing AChE inhibition. Nevertheless, these results are only hypothetical. Penetration of biperiden to tissues and through blood-brain barrier is based on high lipophilicity and furthermore it is not substrate for efflux transporters like P-glycoprotein which eliminate drugs back into blood flow $[27,28]$. At peak concentration of biperiden in plasma, there is approx. $26 \%$ occupancy of mAChR in human brain [26]; however no evidence about molar levels in cerebrospinal fluid was found and hence more investigation could be done this way. On the other hand, cerebrospinal fluid levels of, for example, donepezil, were observed [29] and recently changes in concentration between doses were evaluated [30]. 
Although biperiden is weak inhibitor of AChE and seems to be toxic in high doses, future research based on similar structure derivatives could open interesting direction of AChE inhibitors synthesis and thus in Alzheimer or another neurodegenerative disease treatment.

\section{Conclusion}

Biperiden was revealed to be inhibitor of $\mathrm{AChE}$ in our experiment. However, in comparison with standardly used inhibitors, biperiden is weak inhibitor of AChE; $K_{i}$ was calculated to be $1.11 \mathrm{mmol} / \mathrm{l}$. In real conditions concentration is too low to cause significant inhibition effect; however in high doses it could become toxic. Future perspectives are seen in further investigation of similar derivatives which could create direction in $\mathrm{AChE}$ inhibitors research.

\section{Conflicts of Interest}

The authors declare that there are no conflicts of interest.

\section{Acknowledgments}

This work was supported by Ministry of Defence of the Czech Republic long-term organization development plan, Medical Aspects of Weapons of Mass Destruction of the Faculty of Military Health Sciences, University of Defence.

\section{References}

[1] M. Pohanka, "Acetylcholinesterase inhibitors: a patent review (2008 present)," Expert Opinion on Therapeutic Patents, vol. 22, no. 8, pp. 871-886, 2012.

[2] M. Pohanka, "Cholinesterases, a target of pharmacology and toxicology," Biomedical Papers of the Medical Faculty of the University Palacký, Olomouc, Czechoslovakia, vol. 155, no. 3, pp. 219-230, 2011.

[3] E. Giacobini, "Cholinesterases: new roles in brain function and in alzheimer's disease," Neurochemical Research, vol. 28, no. 3-4, pp. 515-522, 2003.

[4] A. Saxena, A. M. G. Redman, X. Jiang, O. Lockridge, and B. P. Doctor, "Differences in active site gorge dimensions of cholinesterases revealed by binding of inhibitors to human butyrylcholinesterase," Biochemistry, vol. 36, no. 48, pp. 1464214651, 1997.

[5] S. Darvesh, K. V. Darvesh, R. S. McDonald et al., "Carbamates with differential mechanism of inhibition toward acetylcholinesterase and butyrylcholinesterase," Journal of Medicinal Chemistry, vol. 51, no. 14, pp. 4200-4212, 2008.

[6] C. de Los Ríos, "Cholinesterase inhibitors: a patent review (2007-2011)," Expert Opinion on Therapeutic Patents, vol. 22, no. 8, pp. 853-869, 2012.

[7] F. Arduini, F. Ricci, I. Bourais, A. Amine, D. Moscone, and G. Palleschi, "Extraction and detection of pesticides by cholinesterase inhibition in a two-phase system: a strategy to avoid heavy metal interference," Analytical Letters, vol. 38, no. 11, pp. 1703-1719, 2005.

[8] M. Pohanka, "Alzheimer's disease and related neurodegenerative disorders: Implication and counteracting of melatonin," Journal of Applied Biomedicine, vol. 9, no. 4, pp. 185-196, 2011.
[9] M. Pohanka, "Alzheimer's disease and oxidative stress: a review," Current Medicinal Chemistry, vol. 21, no. 3, pp. 356-364, 2014.

[10] M. Pohanka, "Butyrylcholinesterase as a biochemical marker," Bratislava Medical Journal, vol. 114, no. 12, pp. 726-734, 2013.

[11] H. Beckmann and H. W. Moises, "The cholinolytic biperiden in depression - An acute placebo controlled study," Archiv für Psychiatrie und Nervenkrankheiten, vol. 231, no. 3, pp. 213-220, 1982.

[12] E. Wezenberg, R. J. Verkes, B. G. C. Sabbe, G. S. F. Ruigt, and W. Hulstijn, "Modulation of memory and visuospatial processes by biperiden and rivastigmine in elderly healthy subjects," Psychopharmacology, vol. 181, no. 3, pp. 582-594, 2005.

[13] J. Kassa and J. Fusek, "The influence of anticholinergic drug selection on the efficacy of antidotal treatment of somanpoisoned rats," Toxicology, vol. 154, no. 1-3, pp. 67-73, 2000.

[14] J. Kassa, "Importance of cholinolytic drug selection for the efficacy of HI-6 against soman in rats," Toxicology, vol. 116, no. 1-3, pp. 147-152, 1997.

[15] P. Eyer, F. Worek, D. Kiderlen et al., "Molar absorption coefficients for the reduced ellman reagent: reassessment," Analytical Biochemistry, vol. 312, no. 2, pp. 224-227, 2003.

[16] Y. Bourne, J. Grassi, P. E. Bougis, and P. Marchot, "Conformational flexibility of the acetylcholinesterase tetramer suggested by X-ray crystallography," Journal of Biological Chemistry, vol. 274, no. 43, pp. 30370-30376, 1999.

[17] A. Grosdidier, V. Zoete, and O. Michielin, "SwissDock, a protein-small molecule docking web service based on EADock DSS," Nucleic Acids Research, vol. 39, no. 2, pp. W270-W277, 2011.

[18] M. Pohanka, "Biosensors containing acetylcholinesterase and butyrylcholinesterase as recognition tools for detection of various compounds," Chemical Papers, vol. 69, no. 1, pp. 4-16, 2015.

[19] F. Karbassi, A. A. Saboury, M. T. H. Khan, M. I. Choudhary, and Z. S. Saifi, "Mushroom tyrosinase inhibition by two potent uncompetitive inhibitors," Journal of Enzyme Inhibition and Medicinal Chemistry, vol. 19, no. 4, pp. 349-353, 2004.

[20] R. Anjana, M. K. Vaishnavi, D. Sherlin et al., "Aromaticaromatic interactions in structures of proteins and proteinDNA complexes: a study based on orientation and distance," Bioinformation, vol. 8, no. 24, pp. 1220-1224, 2012.

[21] G. B. McGaughey, M. Gagné, and A. K. Rappé, "П-Stacking interactions. Alive and well in proteins," The Journal of Biological Chemistry, vol. 273, no. 25, pp. 15458-15463, 1998.

[22] J.-P. Colletier, D. Fournier, H. M. Greenblatt et al., "Structural insights into substrate traffic and inhibition in acetylcholinesterase," EMBO Journal, vol. 25, no. 12, pp. 2746-2756, 2006.

[23] Q. Zhao and X. C. Tang, "Effects of huperzine A on acetylcholinesterase isoforms in vitro: Comparison with tacrine, donepezil, rivastigmine and physostigmine," European Journal of Pharmacology, vol. 455, no. 2-3, pp. 101-107, 2002.

[24] M. Hollmann, E. Brode, G. Greger, H. Müller-Peltzer, and N. Wetzelsberger, "Biperiden effects and plasma levels in volunteers," European Journal of Clinical Pharmacology, vol. 27, no. 5, pp. 619-621, 1984.

[25] L. H. J. Dieckmann, A. C. Ramos, E. A. Silva et al., "Effects of biperiden on the treatment of cocaine/crack addiction: A randomised, double-blind, placebo-controlled trial," European Neuropsychopharmacology, vol. 24, no. 8, pp. 1196-1202, 2014. 
[26] Y. Sudo, T. Suhara, K. Suzuki et al., "Muscarinic receptor occupancy by biperiden in living human brain," Life Sciences, vol. 64 , no. $8,1999$.

[27] I. S. Abalos, Y. I. Rodríguez, V. Lozano et al., “Transepithelial transport of biperiden hydrochloride in Caco-2 cell monolayers," Environmental Toxicology and Pharmacology, vol. 34, no. 2, pp. 223-227, 2012.

[28] K. M. Mahar Doan, J. E. Humphreys, L. O. Webster et al., "Passive permeability and P-glycoprotein-mediated efflux differentiate central nervous system (CNS) and non-CNS marketed drugs," The Journal of Pharmacology and Experimental Therapeutics, vol. 303, no. 3, pp. 1029-1037, 2002.

[29] T. Darreh-Shori, L. Meurling, T. Pettersson et al., "Changes in the activity and protein levels of CSF acetylcholinesterases in relation to cognitive function of patients with mild alzheimer's disease following chronic donepezil treatment," Journal of Neural Transmission, vol. 113, no. 11, pp. 1791-1801, 2006.

[30] M. Valis, J. Masopust, O. Vysata et al., "Concentration of Donepezil in the Cerebrospinal Fluid of AD Patients: Evaluation of Dosage Sufficiency in Standard Treatment Strategy," Neurotoxicity Research, vol. 31, no. 1, pp. 162-168, 2017. 

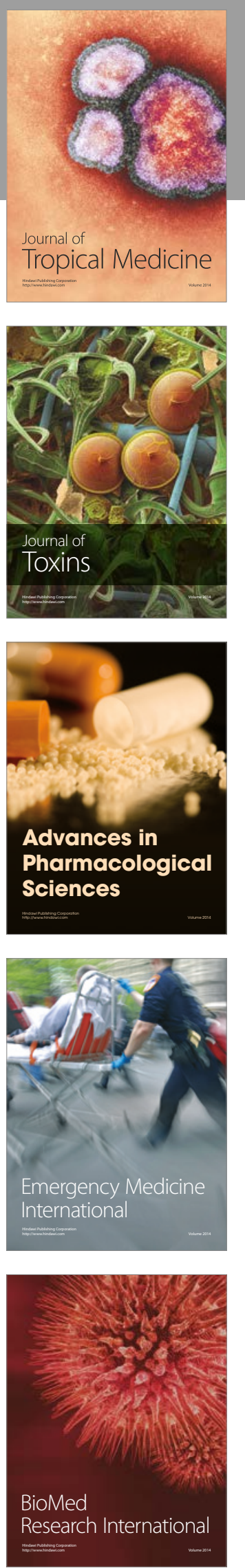
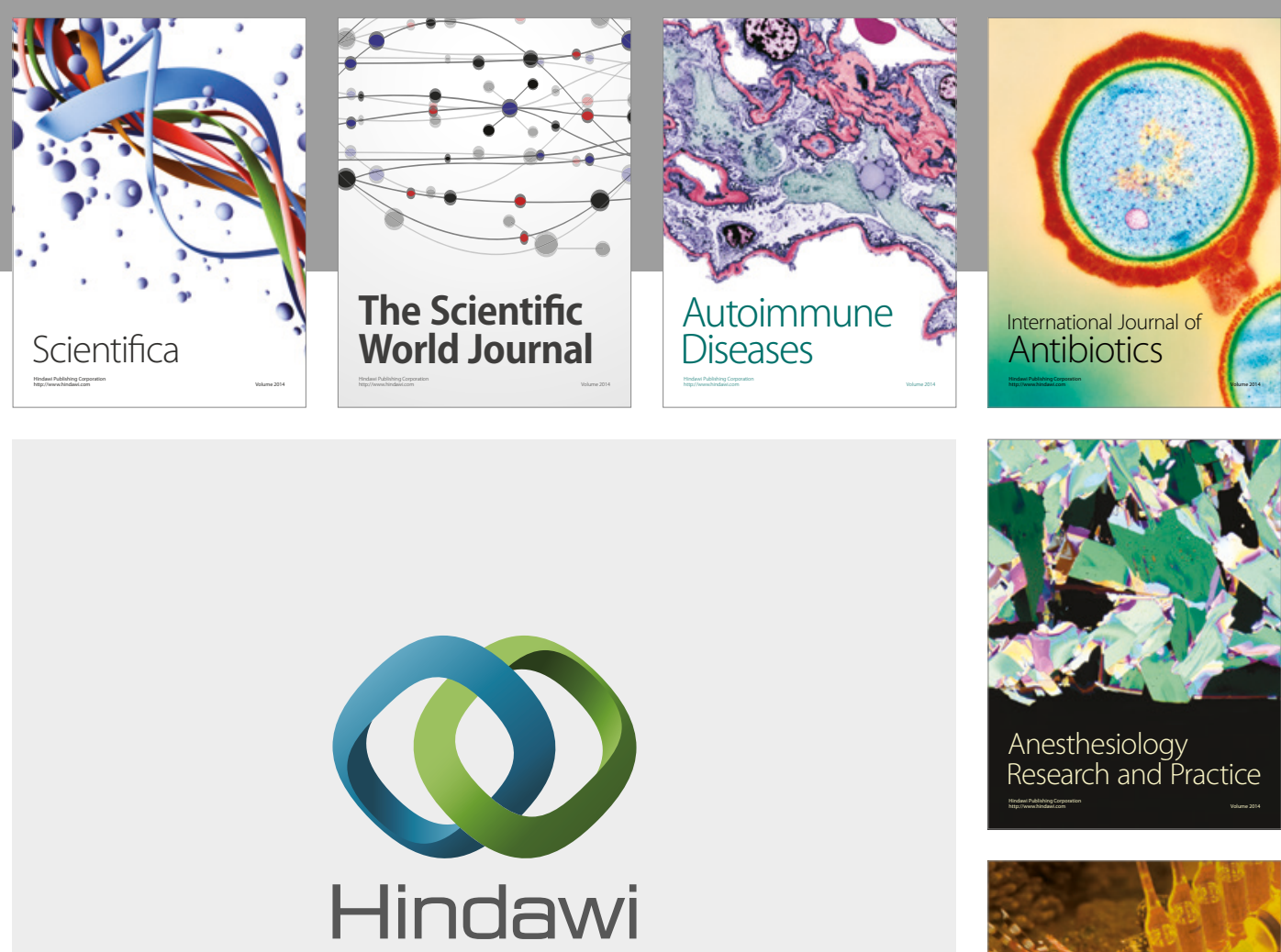

Submit your manuscripts at

https://www.hindawi.com
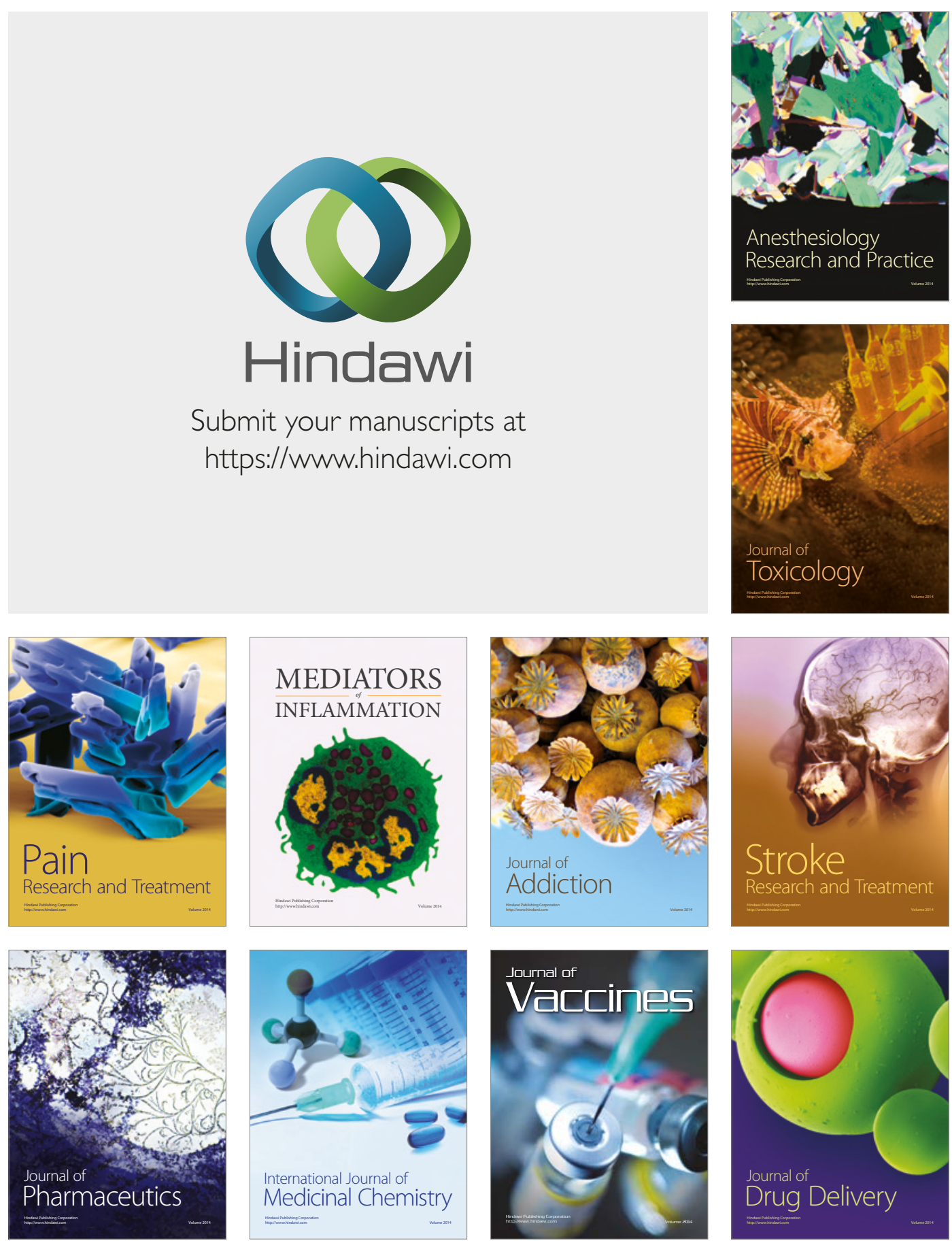